\title{
EFICÁCIA DA MEDIAÇÃO DO PROFESSOR NO ENSINO DA ESTRUTURA CORPUSCULAR DA MATÉRIA
}

\author{
EFFECTIVENESS OF TEACHER MEDIATION IN TEACHING THE \\ CORPUSCULAR STRUCTURE OF MATTER
}

\author{
EFICACIA DE LA MEDIACIÓN DEL PROFESOR EN LA \\ ENSEÑANZA DE LA ESTRUCTURA \\ CORPUSCULAR DE LA MATERIA
}

FÁtima Maria Araújo ${ }^{1}$ J. BERNARDinO LOPES ${ }^{2}$ Armando A. SoARES ${ }^{3}$ José Cravino ${ }^{4}$ ${ }^{1}$ Universidade de Trás-os-Montes e Alto Douro. Portugal ${ }^{2}$ Universidade de Trás-os-Montes e Alto Douro. Portugal ${ }^{3}$ Universidade de Trás-os-Montes e Alto Douro. Portugal ${ }^{4}$ Universidade de Trás-os-Montes e Alto Douro. Portugal

Resumo O objetivo deste estudo foi investigar a influência/eficácia da mediação do professor na aprendizagem da estrutura da matéria e das mudanças de estado físico a nível microscópico, por alunos do $5^{\circ}$. ano de escolaridade. O estudo teve como base duas questões de investigação: 1) "Qual a influência/eficácia da mediação do professor, em tarefas com igual orientação, na compreensão das mudanças de estado físico da matéria, a nível corpuscular, por alunos do $5^{\circ}$. ano de escolaridade?" 2) "Que avaliação o aluno atribui à autonomia dada pela professora?" O estudo foi realizado em dois grupos de 15 alunos cada. Fez-se a recolha de dados sobre o ensino e a aprendizagem em sala de aula em particular gravações áudio, imagens e trabalhos dos alunos. Com esses dados se construíram narrações multimodais, cuja análise permitiu verificar que a mediação do professor foi diferente nos dois grupos e que essa diferença pode ter influenciado o grau de desempenho dos alunos e a percepção da autonomia facultada pela professora.

Palavras-chave: Narrações multimodais; Estados físicos da matéria; Natureza corpuscular da matéria; SimulaÇões computacionais; Mediação do ensino. 
Abstract The purpose of this study was to investigate the influence / effectiveness of teacher's mediation in the learning of the structure of the subject and the changes in physical state at the microscope level, by students of the 5th grade of schooling. The study was based on two research questions: (1) "What is the influence / effectiveness of the teacher's mediation, in tasks with equal orientation, in the understanding of the changes in the physical state of the subject, at the corpuscular level, by students of the 5th year of schooling?" (2) "What assessment does the student attribute to the autonomy given by the teacher?" The study was conducted in two groups of 15 students each. Data on the teaching and learning process were collected, in particular audio recordings, images and student work. With these data were constructed multimodal narrations, whose analysis allowed to verify that the mediation of the teacher was different in the two groups and that this difference may have influenced the degree of performance of the students and the perception of autonomy provided by the teacher.

Keywords: Multimodal narratives; Physical states of matter; Corpuscular nature of matter; Computational simulations; Mediation of education.

Resumen El objetivo de este estudio fue investigar la influencia/eficacia de la mediación del profesor en el aprendizaje de la estructura de la materia y de los cambios de estado físico a nivel microscópico, por alumnos del $5^{\circ}$. año de escolaridad. El estudio se basó en dos preguntas de investigación: 1) "Cuál es la influencia / eficacia de las tareas de mediación maestro con la misma orientación en la comprensión de los cambios de estado físico de la materia, el nivel de partículas, para los estudiantes del quinto año?" 2) "Qué evaluación el alumno atribuye a la autonomía dada por la profesora?" El estudio se realizó en dos grupos de 15 alumnos cada uno. Se hizo la recogida de datos sobre el proceso de enseñanza y aprendizaje en particular grabaciones audio, imágenes y trabajos de los alumnos. Con esos datos se construyeron narraciones multimodales, cuyo análisis permitió verificar que la mediación del profesor fue diferente en los dos grupos y que esa diferencia pudo haber influenciado el grado de desempeño de los alumnos y la percepción de la autonomía facilitada por la profesora.

Palabras clave: Narraciones multimodales; Estados físicos de la materia; La naturaleza corpuscular de la materia; Las simulaciones computacionales; Mediación de la ENSEÑANZA.

\section{INTRODUÇÃo}

As ações de mediação do professor têm influência no envolvimento produtivo dos alunos, sugerem Engle e Conant (2002) e Cunha et al. (2014), e por conseguinte, na sua aprendizagem. Por sua vez, o tema em estudo pelos alunos (natureza corpuscular da matéria) é muito abstrato. Apesar de se recorrer à exploração de simulações computacionais pelos alunos, estas não garantem per se a aprendizagem dos alunos. Importa saber que ações de mediação do professor favorecem a aprendizagem da estrutura da matéria e das mudanças 
de estado físico a nível microscópico pelos alunos do $5^{\circ}$. ano de escolaridade quando estes utilizam, como ferramenta, as simulações computacionais. Num estudo de investigação, Cunha et al. (2014) concluíram que determinadas ações de mediação do professor estão associadas a um maior envolvimento produtivo do aluno enquanto outras o reduzem. Assim, "incentivar o envolvimento dos alunos na tarefa, estimular a problematização e monitorizar de modo sistemático o envolvimento dos alunos sem lhes retirar autoridade, são ações de mediação associadas a um maior envolvimento produtivo onde os produtos das tarefas se relacionam com a utilização efetiva de simulações computacionais" (CUNHA et al., 2014, p. 84). Por sua vez, se o professor constantemente interferir na atividade do aluno, se responder de imediato às questões que lhe são colocadas, privando os alunos de obterem por si próprios as respostas, pode levar a situações de não envolvimento ou a uma redução do envolvimento produtivo (CUNHA et al., 2014). Deste modo, é pertinente investigar a influência/eficácia da mediação do professor na aprendizagem da estrutura da matéria e das mudanças de estado físico a nível microscópico, por alunos do $5^{\circ}$. ano de escolaridade.

A teoria corpuscular da matéria poderá ser entendida por alunos do $5^{\circ}$. ano de escolaridade?

Muitos consideram que a introdução da teoria corpuscular da matéria numa fase precoce, em que as crianças ainda não têm capacidade de abstração, é pouco útil. Contudo, Löfgren e Helldén (2008) e Novak e Musonda (1991) têm a opinião, fundamentada nos seus trabalhos de investigação, de que a introdução dessa teoria mais cedo ajuda os alunos a compreenderem a teoria cinético-molecular e possibilita conectá-las com as ideias prévias e elaborar uma compreensão gradual dos conceitos (NAKHLEH; SAMARAPUNGAVAN, 1999).

Na educação em ciências, os modelos científicos ajudam os estudantes a envolver-se e a refletirem sobre ciência (TORRES; VASCONCELOS, 2015) bem como, desenvolver os seus próprios modelos mentais de conceitos científicos (TREAGUST; CHITTLEBOROUGH; MAMIALA, 2002).

As simulações computacionais (SC) no ensino podem ser instrumento importante na compreensão de fenômenos que exigem alguma abstração, uma vez que possibilitam a visualização dos modelos que descrevem esses fenômenos e "permitem ao aluno construir o seu conhecimento conduzindo experiências e observando os seus efeitos" (OLYMPIOU; ZACHARIAS; DE JONG; 2013, p. 576) ou construir uma compreensão mais profunda do que está à nossa volta.

Contudo, o trabalho com SC permanece, muitas vezes, a um nível superficial e lúdico. A atenção dada pelos alunos aos aspectos visuais da interface pode reduzir as potencialidades das SC na eficácia da aprendizagem. Os alunos não fazem suposições sobre o controle de variáveis modificáveis. Uma autonomia não orientada pode assim ser ineficaz (DE JONG; VAN JOOLINGEN, 1998).

Os alunos precisam de apoio para ultrapassar as dificuldades em determinadas tarefas, como tirar conclusões a partir dos dados (ALFIERI; BROOKS; ALDRICH; TENENBAUM, 2011). O professor tem um papel importante na orientação e apoio que fornece aos alunos em sala de aula (e. g., OSBORNE; DILLON, 2010; SMETANA; BELL, 2012). 
No entanto, muita orientação pode criar nos alunos uma sensação de dependência. Um nível de suporte alto, durante algum tempo, pode resultar na formulação de conhecimento de conteúdo em vez de compreensão de conteúdo. O conhecimento do conteúdo pode ser recuperado da memória de longo prazo, mas não pode ser aplicado em situações diferentes (MOLI; DELSERIEYS; IMPEDOVO; CASTERA, 2017).

\section{A IMPORTÂNCIA do PROFESSOR COMO MEDIADOR DA APRENDIZAGEM}

Os professores desempenham um papel central na orientação da aprendizagem por inquérito com utilização de SC. Independentemente da fonte da orientação (SMETANA; BELL, 2012), essa orientação deve ser sempre adaptada às necessidades dos alunos, ao seu conhecimento e experiência (HSU; GAO; LIU; SWELLER, 2015).

As decisões pedagógicas que o professor toma são da sua responsabilidade, mas estas dependem do comportamento dos alunos, da interação destes com os seus pares, com o professor e com o objeto epistêmico que interagem (LOPES; CRAVINO; SILVA, 2010a).

Para Engle e Conant (2002), o envolvimento é produtivo quando os alunos fazem progressos intelectuais. O que constitui produtividade depende da disciplina, da tarefa, do tema específico e onde os alunos se situam cognitivamente quando começam a resolver um problema.

O modelo teórico de Lopes, Cravino e Silva (2010), o Modelo de Situação Formativa para o Ensino de Ciência e Tecnologia (MSF/ECT), que identifica a eficácia de determinado método de ensino, considera que a mediação do professor apresenta duas dinâmicas fundamentais: 1) a interação com o objeto epistêmico; 2) a interação com os outros. Destaca ainda seis componentes-chave: os mediadores, o outro, o objeto epistêmico, o processo de aprendizagem, a tarefa/ desafio de aprendizagem e a aprendizagem. Esse modelo propõe que a conjugação e os vínculos que se estabelecem entre as dinâmicas e os componentes possam ser analisados por meio de dez dimensões.

Neste trabalho descritivo, algumas das dimensões do Modelo teórico de Lopes; Cravino e Silva (2010) vão ser objeto de análise.

\section{Problema de investigaÇão}

Apesar dos alunos gostarem de trabalhar com simulações computacionais e a sua exploração "desencadear nos alunos reações muito positivas" (MORAIS; PAIVA, 2007, p. 110) nem sempre resulta aprendizagem.

O professor, mediador do ensino, deve orientar a tarefa no sentido de apoiar, de dar suporte efetivo aos alunos na realização da tarefa. $\mathrm{O}$ modo como o professor o faz pode ser determinante para a eficácia das aprendizagens dos alunos, quando esses utilizam as simulações como ferramenta epistêmica.

O objetivo deste estudo foi investigar a influência/eficácia da mediação do professor na aprendizagem de conceitos acerca da estrutura da matéria e das mudanças de estado físico a nível microscópico, por alunos do $5^{\circ}$. ano de escolaridade. 
Assim, procurou-se responder às seguintes questões de investigação: Qual a influência/eficácia da mediação do professor, em tarefas com igual orientação, na compreensão das mudanças de estado físico da matéria, a nível corpuscular, por alunos do $5^{\circ}$. ano de escolaridade? Que avaliação o aluno atribui à autonomia dada pela professora? Foi analisada e avaliada a mediação efetuada pela professora, em dois grupos de alunos, durante a aula de exploração da simulação computacional. Por sua vez, a percepção dos alunos sobre o clima de sala de aula e autonomia dada pela professora foi avaliada por intermédio de um questionário adaptado da Learning Climate Questionnaire of Williams \& Deci (1996).

\section{Metodologia}

Trata-se de um estudo de natureza qualitativa/interpretativa de análise de conteúdo de narrações multimodais.

Para Bardin (2009), a análise de conteúdo consiste num conjunto de técnicas de análise de comunicações que usam procedimentos sistemáticos e objetivos de descrição do conteúdo das mensagens.

Portanto, a análise de conteúdo é uma metodologia que possibilita a interpretação do conteúdo de diversos tipos de documentos, como, narrações multimodais, entrevistas, textos, jornais, revistas, relatos autobiográficos etc. É uma abordagem metodológica em que se analisa, interpreta e categoriza os dados que se quer investigar, fazendo inferências a partir deles. Essa metodologia assenta na interpretação dos dados disponíveis e parte do pressuposto de que em qualquer documento se podem identificar palavras, frases, expressões ou associações que são suscetíveis de serem categorizadas.

Uma narração multimodal é uma descrição multimodal, autocontida, fidedigna e pública de práticas profissionais em contexto real de trabalho (LOPES, et al. 2014; LOPES, VIEGAS; PINTO, 2018, p. 22). Pode ser utilizada para verificar em que condições, determinado aspecto da prática de ensino funciona e é efetivo, pois "relata de forma holística e multimodal o que se passou nas aulas conciliando informação objetiva e verificável com a descrição de intenções e decisões do professor na perspetiva do professor" (LOPES, 2018, p. 36). "Permitem ao professor e/ou investigador a escolha de variados ângulos de análise capazes de detalharem a riqueza do ambiente natural de sala de aula" (SOARES, 2018, p. 243). "São um instrumento metodológico consolidado de investigação e de aferição do ensino e da aprendizagem em sala de aula" (SOARES, 2018, p. 243).

Apesar de os professores geralmente refletirem a respeito das suas práticas, essa reflexão em geral é subjetiva, tácita e acrítica. Ela deve basear-se em fatos observados, concretos e registrados e deve ser realizada de forma sistemática. "Investigar sobre práticas de ensino exige conhecer essas práticas e conhecê-las de modo completo em toda a sua complexidade" (COSTA; GONÇALVES,-2018, p. 129).

As narrações multimodais permitem a recolha e organização de dados sobre a prática efetiva do professor em sala de aula e podem ajudar a compreender que práticas do professor promovem aprendizagens de qualidade, e que modificações curriculares iterativas, 
postas em prática em sala de aula, se revelam produtivas (ou não) no sucesso didático das práticas e no sucesso acadêmico dos alunos (CRAVINO, 2018).

Neste trabalho, as narrações multimodais foram utilizadas como instrumento de organização de dados recolhidos das práticas de ensino da professora/investigadora e sujeitas à análise de conteúdo a fim de investigar a influência da mediação do professor no ensino da natureza corpuscular da matéria no $5^{\circ}$. ano de escolaridade. As narrações multimodais das aulas foram elaboradas pela professora a partir da recolha de dados (gravações áudio, trabalho dos alunos, imagens) e foi posteriormente validada por dois investigadores externos, em ambos os processos seguindo o protocolo prescrito (Lopes et al., 2014).

Este estudo envolveu trinta alunos, do $5^{\circ}$. ano de escolaridade, divididos em dois grupos de quinze alunos cada. A divisão foi feita de modo a que o número de alunos dos gêneros feminino e masculino fosse próximo e que cada grupo tivesse 15 alunos. De maneira que não perturbasse as restantes atividades curriculares e extracurriculares dos alunos, optou-se por fazer um grupo com 15 alunos de uma turma e um grupo com alunos desta e de mais duas turmas (amostragem conveniente). Enquanto o Grupo 1 era constituído por alunos da mesma turma, o Grupo 2 era constituído por alunos de três turmas. Também o número de alunos sem computador pessoal era superior no Grupo 2.

O Grupo 1, com oito estudantes do gênero feminino e sete do gênero masculino, era oriundo da mesma turma, e o Grupo 2, com seis estudantes do gênero feminino e nove do gênero masculino, provinha de três turmas distintas. Os alunos tinham idades compreendidas entre 9 anos e 12 anos. Três alunos do Grupo 1 e cinco do Grupo 2 não tinham computador pessoal.

A professora da disciplina foi a professora investigadora. A professora é licenciada em Ciências Farmacêuticas e mestre em Biotecnologia - Engenharia de Bioprocessos. Tem formação na área da química e da biologia e leciona há 29 anos. Iniciou a docência como professora de Ciências da Natureza e Matemática do $5^{\circ}$. e $6^{\circ}$. anos de escolaridade e Ciências Naturais numa turma de adultos. Foi professora de Físico-Química do $9^{\circ}$. ano de escolaridade e lecionou a área de Sociedade Tecnologia e Ciência aos alunos de Educação e Formação de Adultos de nível Secundário. Atualmente, leciona Ciências Naturais e Matemática.

Os alunos exploraram a simulação computacional "states-of-matter-basics" do PhET da Universidade do Colorado (versão traduzida em português). A simulação foi usada para introduzir a natureza corpuscular da matéria e as mudanças de estado físico da matéria com as variações de temperatura e pressão a nível corpuscular. Os alunos exploraram a simulação em pares, exceto um aluno em cada grupo que esteve só. Foi distribuída uma ficha de trabalho para os alunos realizarem durante a exploração da simulação. As fichas de trabalho distribuídas aos alunos eram iguais para os dois grupos. A ficha de trabalho estava dividida em duas partes: a primeira parte com a introdução, que apresentava o fenômeno a ser investigado, a simulação computacional, as variáveis a manipular e a questão de trabalho; a segunda parte tinha três tarefas: na primeira tarefa um quadro para os alunos descreverem as semelhanças e diferenças da água e do oxigênio nos três estados físicos da matéria; a segunda tarefa tinha também dois esquemas para os alunos completarem, relacionados com 
a alteração das variáveis durante o aquecimento e o arrefecimento; a terceira tarefa tinha um esquema para completarem relacionada com a alteração de variáveis na compressão de materiais (Figura 1).

Figura 1 - Esquemas colocados na ficha de trabalho para os alunos relacionarem variáveis.

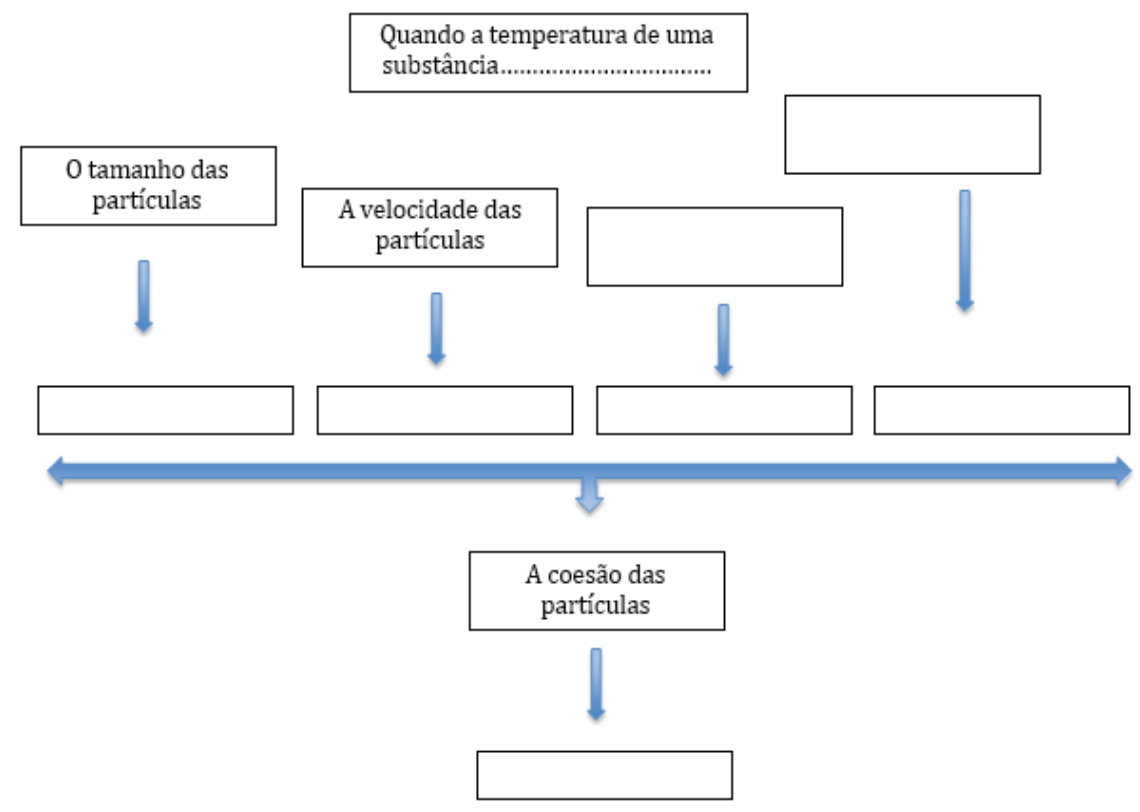

Os alunos tiveram autonomia para explorarem a simulação computacional, fazer as suas observações, recolher, registrar e organizar os dados necessários para responderem à questão de trabalho e chegar a uma conclusão. Apesar de os alunos terem autonomia para explorarem a simulação computacional essa estava, implicitamente, condicionada pela estrutura e organização da ficha de trabalho. No fim da exploração da simulação computacional, os alunos responderam a um questionário confidencial, o Perceived Autonomy Support: The Learning Climate Questionnaire (Figura 2), com o objetivo de avaliarem o clima de sala de aula e a percepção que tiveram da autonomia proporcionada na exploração da simulação. O questionário com seis itens concorre para um único fator que avalia a percepção do suporte de autonomia dado pela professora. A resposta é dada numa escala tipo Likert de 1-7, correspondendo à opção "Discordo Totalmente" ao valor 1 e o "Concordo totalmente" ao valor 7. A pontuação foi calculada por intermédio da média das pontuações dos itens individuais.

Foram construídas narrações multimodais a partir da recolha de dados das aulas como gravações áudio, fichas de trabalho, feitas pelos alunos no decurso da exploração da simulação, fotos e anotações do decurso das aulas realizadas pela docente. 
Figura 2 - Questionário de avaliação do suporte de autonomia na exploração da simulação.

Este questionário contém itens relacionados com a experiência que teve, nesta aula, com o (a) professor (a). Os professores têm estilos diferentes de trabalhar com os alunos, e gostariamos de saber sobre o modo como sentiu ser o seu relacionamento com a professora nesta aula. As suas respostas são confidenciais. Por favor seja honesto(a) e sincero(a).

Coloque um algarismo em cada linha e na coluna que corresponde à classificação da sua opinião|

\begin{tabular}{|c|c|c|c|c|c|c|c|}
\hline \multirow[t]{2}{*}{ Questões } & $\begin{array}{c}\text { Discordo } \\
\text { completamente }\end{array}$ & $\begin{array}{l}\text { Discordo um } \\
\text { pouco }\end{array}$ & Discordo & $\begin{array}{l}\text { Nem } \\
\text { discordo nem } \\
\text { concordo }\end{array}$ & $\begin{array}{l}\text { Concordo } \\
\text { um pouco }\end{array}$ & Concordo & $\begin{array}{c}\text { Concordo } \\
\text { completamente }\end{array}$ \\
\hline & 1 & 2 & 3 & 4 & 5 & 6 & 7 \\
\hline \multicolumn{8}{|l|}{$\begin{array}{l}\text { 1. Sinto que me foi permitido fazer escolhas e } \\
\text { opções na exploração da gimulação } \\
\text { computacional }\end{array}$} \\
\hline \multicolumn{8}{|l|}{$\begin{array}{l}\text { 2.Sinto que as minhas op̧̧̃es foram } \\
\text { compreendidas pela professora. }\end{array}$} \\
\hline \multicolumn{8}{|l|}{$\begin{array}{l}\text { 3.O professora tranamitiu-me confiança sobre } \\
\text { a minha capacidade para realizar a tarefa. }\end{array}$} \\
\hline \multicolumn{8}{|l|}{$\begin{array}{l}\text { 4.Fui encorajado pela professora a fazer } \\
\text { perguntas. }\end{array}$} \\
\hline \multicolumn{8}{|l|}{$\begin{array}{l}\text { 5. A minha opinião sobre a forma como optei } \\
\text { por fazer as coisas foi ouvida pela professora. }\end{array}$} \\
\hline $\begin{array}{l}\text { 6. A professora tentou entender as minhas } \\
\text { opções na exploração da simulação antes de } \\
\text { sugerir uma nova maneira de a explorar. }\end{array}$ & & & & & & & \\
\hline
\end{tabular}

\section{AnÁlise dos dados}

A mediação do professor foi estudada por meio da análise de conteúdo das narrações multimodais das aulas.

$\mathrm{Na}$ análise das narrações multimodais, procurou-se verificar se houve diferenças na mediação/orientação de ensino da professora, nos dois grupos de alunos, durante as aulas onde houve exploração da SC. Ao mesmo tempo, também se fez a análise da dimensão "Aprendizagem do aluno".

Definiram-se assim três categorias na dimensão "mediação do professor": 1) Dá autonomia aos alunos; 2) Promove envolvimento do aluno; 3) Proporciona indução de elaboração conceptual. Cada categoria ainda foi dividida em subcategorias. A categoria um está dividida em duas subcategorias. A primeira diz respeito à autonomia proporcionada pela professora na gestão da tarefa pelo aluno e a segunda à autonomia na exploração da simulação computacional. A categoria dois está dividida em três subcategorias: contextualização da tarefa pela professora; fornecer informação; orientação da simulação. A terceira categoria tem também três subcategorias: solicita informação do aluno; solicita compreensão do aluno; solicita construção ou desenvolvimento pelo aluno. Relativamente à dimensão "Aprendizagem do aluno", foram definidas igualmente três categorias: 1) Autonomia do aluno; 2) Envolvimento do aluno; 3) Elaboração conceptual. A dimensão mediação do professor diz respeito às ligações ou conjugações e vínculos que se estabelecem entre a interação com o objeto epistêmico, a simulação computacional, e a interação com os alunos. Esta é analisada na categoria "dá autonomia aos alunos", que significa o espaço que é proporcionado aos alunos, respeitando as suas decisões e opções, quer para explorarem a simulação computacional, podendo selecionar algumas das variáveis com que querem 
trabalhar, quer a gestão das próprias tarefas, embora os alunos desse nível etário são muito condicionados pelo próprio guião das tarefas. Também é analisada na categoria "promove envolvimento do aluno", ou seja, ações do professor que promovam empenho, interesse e entusiasmo dos alunos na resolução das tarefas e com sucesso. O envolvimento do aluno depende de vários fatores. Entre eles: se o professor faz a contextualização da tarefa, se fornece a informação necessária e pertinente aos alunos de modo a que estes consigam atingir os objetivos propostos na tarefa, não esquecendo que o objetivo final e principal é o conhecimento do assunto que está a ser estudado e as competências que o aluno adquire com esse conhecimento. Orienta-se a tarefa sempre que seja necessário para o aluno ultrapassar dificuldades. Por último, também é analisada na categoria "Proporciona indução da elaboração conceptual". Isso significa que o professor questiona o aluno no sentido de ajudá-lo na observação dos fenômenos e na identificação e compreensão da relação entre as variáveis. A escolha das categorias da dimensão mediação foi inspirada no modelo teórico de Lopes, Cravino e Silva (2010), o Modelo de Situação Formativa para o Ensino de Ciência e Tecnologia (MSF/ECT).

A dimensão "aprendizagem do aluno" se refere como o nome indica à aprendizagem e, por conseguinte, compreensão do conteúdo que o aluno está a estudar, a natureza corpuscular da matéria e o fenômeno da alteração do estado físico a nível microscópico por alteração da temperatura. As categorias estão em alinhamento com as categorias relativas à dimensão mediação do professor. A categoria "autonomia" se refere à capacidade de o aluno gerir as suas tarefas e explorar a simulação computacional com pouca dependência do professor. A categoria "envolvimento do aluno" se refere ao empenho do aluno na realização efetiva das tarefas e à solicitação de informação e orientação na exploração computacional toda vez que for necessário para ultrapassar dificuldades que possam impedir a consecução da tarefa. Por fim, a categoria "elaboração conceptual" diz respeito ao conhecimento que o aluno demonstra possuir. Se este se encontra apenas ao nível da identificação dos fenômenos ou se o aluno compreende e estabelece relações mais complexas entre variáveis ou entre fenômenos, por exemplo, entre o comportamento da matéria a nível macroscópico e o comportamento a nível microscópico.

Tabela 1 - Dimensão mediação do professor e dimensão aprendizagem do aluno, categorias e subcategorias.

\begin{tabular}{|c|c|c|c|c|c|c|c|}
\hline \multicolumn{8}{|c|}{ DIMENSÃO MEDIACÃO } \\
\hline \multicolumn{2}{|c|}{$\begin{array}{c}\text { Dá autonomia aos } \\
\text { alunos }\end{array}$} & \multicolumn{4}{|c|}{ Promove envolvimento do aluno } & \multicolumn{2}{|c|}{$\begin{array}{l}\text { Proporciona indução de } \\
\text { elaboração conceptual }\end{array}$} \\
\hline $\begin{array}{l}\text { Gestão } \\
\text { das } \\
\text { tarefas }\end{array}$ & $\begin{array}{l}\text { Exploração da } \\
\text { SC }\end{array}$ & $\begin{array}{c}\text { Contextualizaçã } \\
\text { da tarefa }\end{array}$ & $\begin{array}{l}\text { Forne } \\
\text { informa }\end{array}$ & & $\begin{array}{l}\text { Orientação da } \\
\text { tarefa }\end{array}$ & Identificação & Compreensão \\
\hline \multicolumn{8}{|c|}{ APRENDIZAGEM DO ALUNO } \\
\hline \multicolumn{2}{|c|}{ Autonomia } & \multicolumn{4}{|c|}{ Envolvimento do aluno } & \multicolumn{2}{|c|}{ Elaboração conceptual } \\
\hline $\begin{array}{c}\text { Gestão } \\
\text { das tarefas }\end{array}$ & $\begin{array}{c}\text { Exploração } \\
\text { da SC }\end{array}$ & $\begin{array}{c}\text { Realização da } \\
\text { tarefa }\end{array}$ & $\begin{array}{c}\text { Solicita } \\
\text { informação }\end{array}$ & & $\begin{array}{c}\text { Solicita } \\
\text { entação na SC }\end{array}$ & Identificação & Compreensão \\
\hline
\end{tabular}


Como é evidente, só é possível saber qual o tipo de elaboração conceptual do aluno a partir das questões colocadas pelo professor ao aluno e das suas respostas ou pelas respostas às tarefas. $\mathrm{O}$ diálogo entre os alunos poderia ser uma fonte profícua de evidências, mas não foram estudadas dada a dificuldade de obter esses dados, pois só foram gravados os diálogos que se estabeleceram entre a professora e os alunos. Não havia gravador para cada grupo de alunos e daí a impossibilidade de se registrar os diálogos entre eles. Contaram-se as intervenções totais da professora e dos alunos, as respostas dadas na ficha de atividades e as situações manifestadas em sala de aula em cada dimensão, quer da dimensão mediação quer da dimensão interesse do aluno.

\section{Resultados}

Da análise das narrações multimodais e confrontando o número de ocorrências em sala de aula, se verificam algumas diferenças relativamente aos dois grupos quer na dimensão mediação do professor quer na dimensão aprendizagem do aluno. Relativamente à categoria "Dá autonomia aos alunos", verifica-se que a professora deu mais autonomia ao grupo 1, quer na gestão das tarefas quer na exploração da simulação computacional, do que ao grupo 2 (Tabela 3 ).

Relativamente à autonomia dada aos alunos, não há grandes diferenças entre os dois grupos. No entanto, o Grupo 2 teve menos autonomia. Por exemplo, nesse grupo, apesar de a professora, inicialmente, ter dito aos alunos para trabalharem com a temperatura em graus Celsius, ela permitiu que um dos grupos trabalhasse em kelvin.

O Alexandre pediu-me para passar de graus centígrados para kelvin. Ajudei-o.

Alexandre: Eu quero passar de centígrados para kelvin. Como é que faço?

Professora: Zero kelvin é a mesma coisa que $-273^{\circ} \mathrm{C}$.

Rui: Eu disse-te!

Professora: No zero absoluto! Como estão as partículas?

Alexandre: Todas paradinhas.

Na categoria "Promove envolvimento do aluno", a professora fornece menos informação aos alunos e orienta mais a tarefa no Grupo 2. Assim, verifica-se que o Grupo 2 teve quase o triplo de situações em que houve orientação da tarefa pela professora (Tabela 2). Por sua vez, inquiriu mais e forneceu menos informação aos alunos do Grupo 2 do que aos do Grupo 1 (Tabela 2). 
Tabela 2 - Número de situações manifestadas em sala de aula relativas à dimensão Mediação.

DIMENSÃO MEDIAÇÃO do professor

\begin{tabular}{|c|c|c|c|c|c|c|c|}
\hline \multirow[b]{2}{*}{$\bar{\mho}$} & \multicolumn{2}{|c|}{$\begin{array}{c}\text { Dá autonomia } \\
\text { aos alunos }\end{array}$} & \multicolumn{3}{|c|}{ Promove envolvimento do aluno } & \multicolumn{2}{|c|}{$\begin{array}{l}\text { Proporciona indução de } \\
\text { elaboração conceptual }\end{array}$} \\
\hline & $\begin{array}{c}\text { Gestão } \\
\text { das } \\
\text { tarefas }\end{array}$ & $\begin{array}{l}\text { Exploração } \\
\text { da SC }\end{array}$ & $\begin{array}{c}\text { Contextualização } \\
\text { da tarefa }\end{array}$ & $\begin{array}{l}\text { Fornece } \\
\text { informação }\end{array}$ & $\begin{array}{l}\text { Orientação } \\
\text { da tarefa }\end{array}$ & Identificação & Compreensão \\
\hline \multicolumn{8}{|c|}{ Número de situações manifestadas em sala de aula } \\
\hline 1 & 2 & 14 & 2 & 24 & 36 & 55 & 6 \\
\hline 2 & 1 & 12 & 2 & 17 & 92 & 86 & 7 \\
\hline
\end{tabular}

Quanto à dimensão "Aprendizagem do aluno", verifica-se uma menor autonomia dos alunos do Grupo 2, quer na gestão das tarefas quer na exploração da simulação computacional comparativamente aos do Grupo 1 (Tabela 3). Relativamente ao envolvimento do aluno, verifica-se que no Grupo 1 há menor solicitação de informação e orientação do que no Grupo 2. Também o número de questões que os alunos respondem é superior no Grupo 2, o que está de acordo com o número de questões que o professor coloca para esse grupo.

Tabela 3 - Número de ocorrências em sala de aula relativas à aprendizagem do aluno.

\section{APRENDIZAGEM DO ALUNO}

\begin{tabular}{|c|c|c|c|c|c|c|c|}
\hline & \multicolumn{2}{|c|}{ Autonomia dos alunos } & \multicolumn{3}{|c|}{ Envolvimento do aluno } & \multicolumn{2}{|c|}{ Elaboração conceptual } \\
\hline$\zeta$ & $\begin{array}{l}\text { Gestão das } \\
\text { tarefas }\end{array}$ & $\begin{array}{l}\text { Exploração da } \\
\text { SC }\end{array}$ & $\begin{array}{l}\text { Realização da } \\
\text { tarefa }\end{array}$ & $\begin{array}{l}\text { Solicita } \\
\text { informação }\end{array}$ & $\begin{array}{l}\text { Solicita } \\
\text { orientação } \\
\text { na SC }\end{array}$ & Identificação & Compreensão \\
\hline \multicolumn{8}{|c|}{ Número de situações manifestadas em sala de aula } \\
\hline 1 & 3 & 19 & 14 & 21 & 7 & 67 & 8 \\
\hline 2 & 1 & 8 & 14 & 27 & 24 & 88 & 8 \\
\hline
\end{tabular}

O número de intervenções totais tanto dos alunos do Grupo 2 como da professora nesse grupo é superior às intervenções totais do Grupo 1 (Figura 3). O número de intervenções totais é indicador da maior ou menor autonomia concedida aos alunos (mais intervenções do professor e alunos significa que dedicam menor tempo ao trabalho autônomo).

Os resultados do questionário Perceived Autonomy Support: The Learning Climate Questionnaire - média das pontuações dos itens individuais - revelam que os alunos do 
Grupo $2(5,9)$ sentiram que lhes foi proporcionada menor autonomia na exploração da simulação do que os do Grupo $1(6,2)$. Esses resultados estão em linha como os anteriores: a percepção de autonomia dos alunos é coerente com o tempo de trabalho autônomo.

Figura 3 - Número total de intervenções orais dos alunos e da professora nos dois grupos.

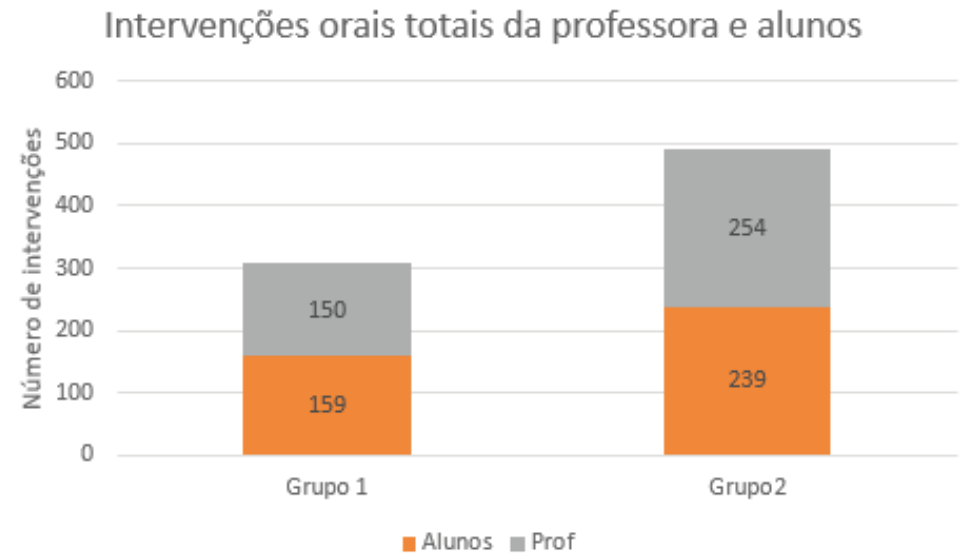

A análise das fichas de trabalho permitiu verificar que o desempenho dos alunos do Grupo 1 foi superior aos do Grupo 2 como se pode observar na Figura 4.

Figura 4 - Resultados das fichas de trabalho dos dois grupos.

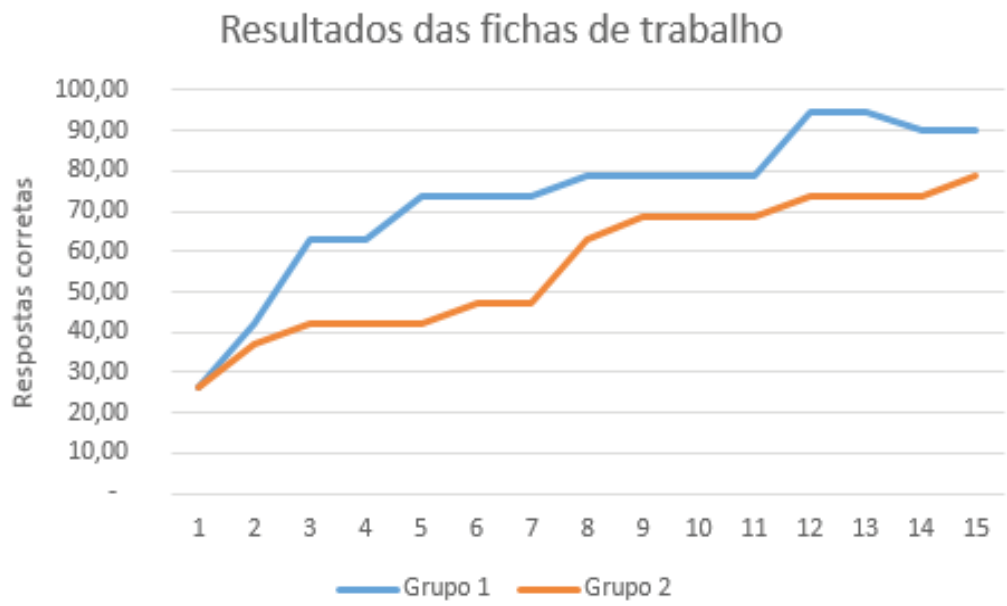

De um modo geral os alunos, tanto de um grupo como do outro, tiveram alguma dificuldade em descrever as semelhanças e diferenças entre a água e o oxigênio. No entanto, o Grupo 2 teve menor desempenho (Figura 5). Em algumas descrições os alunos omitem palavras. Por exemplo, um aluno do Grupo 2, relativamente às diferenças entre a água e o 
oxigênio no estado sólido, diz o seguinte: "no oxigênio é menor porque as partículas ficam mais juntas".

Figura 5 - Resultados dos Grupos 1 e 2 em cada tarefa.

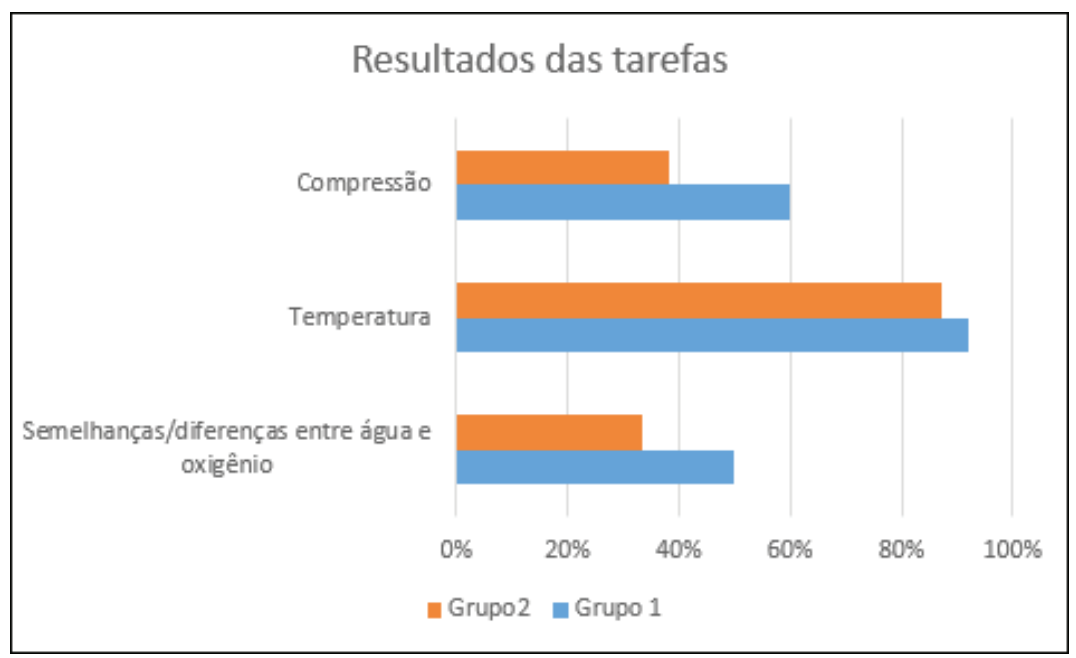

O aluno, provavelmente, queria dizer que, no estado sólido, o espaço entre as partículas do oxigênio é menor porque as partículas ficam mais juntas. Esse aluno em vez de referir uma semelhança entre o oxigênio e a água no estado líquido escreveu uma diferença "As partículas, na água são mais rápidas do que as partículas do oxigênio" (Figura 6a).

Figura 6 - Respostas de alunos: a) um do Grupo 2 b) um do Grupo 1.
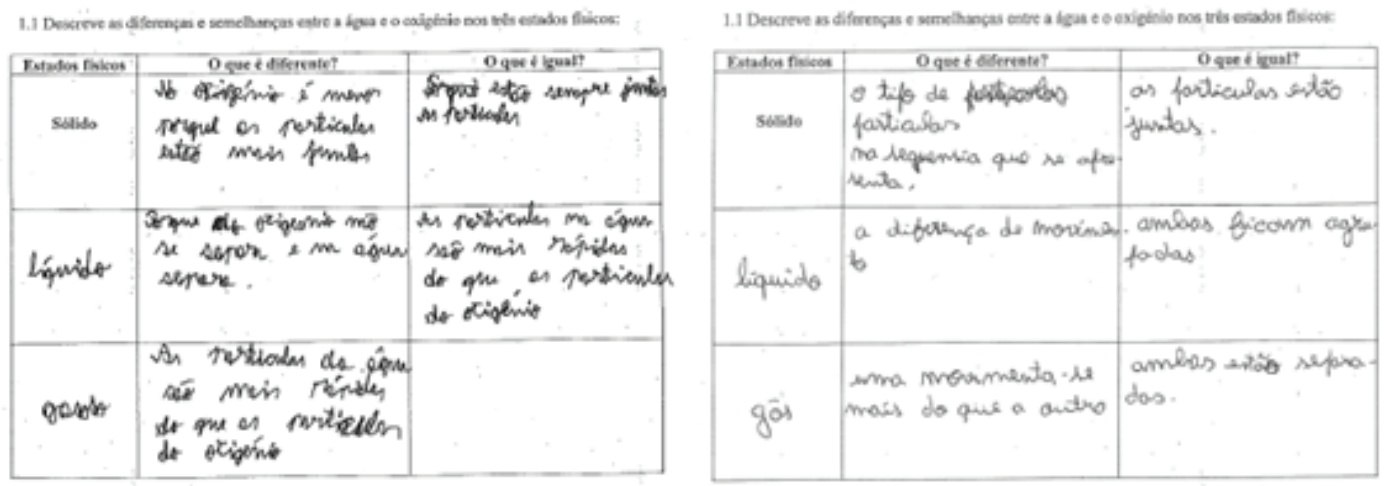

Um aluno do Grupo 1 escreveu "o tipo de partículas na sequência que se apresenta" como resposta ao que é diferente entre a água e o oxigênio no estado sólido. O desempenho dos alunos, tanto os do Grupo 1 como os do Grupo 2, foi superior na tarefa 2 onde se pretendia que relacionassem a variação da temperatura com as outras variáveis.

Durante a mediação em sala de aula, houve uma maior orientação da tarefa pela professora no Grupo 2, e menor autonomia concedida aos alunos. A professora também inqui- 
riu mais os alunos desse grupo. A maior orientação da tarefa por parte da professora se deve à sua percepção inicial de uma menor concentração dos alunos nas tarefas.

Uma maior orientação da tarefa por parte da professora parece relacionada com menor aprendizagem dos alunos. Também uma maior intervenção por parte da professora parece relacionada com menor autonomia e esta pode ter tido influência no envolvimento produtivo do aluno.

\section{Discussão}

De modo a responder às questões de investigação "Qual a influência/eficácia da mediação do professor, em tarefas com igual orientação, na compreensão das mudanças de estado físico da matéria a nível corpuscular, por alunos do $5^{\circ}$. ano de escolaridade", e "Que avaliação o aluno atribui à autonomia dada pela professora?", fez-se a análise das narrações multimodais das aulas de dois grupos de alunos que exploraram a simulação computacional states-of-matter-basics para estudar a natureza corpuscular da matéria e as alterações de estado físico. A análise das narrações multimodais permitiu verificar que a mediação da professora foi ligeiramente diferente nos dois grupos. O Grupo 2 teve maior orientação da tarefa e maior orientação na exploração da simulação computacional do que o Grupo 1. Os alunos do Grupo 2 também solicitaram maior orientação na execução da tarefa do que os alunos do Grupo 1. O número de questões orais colocadas pela professora também foi superior no Grupo 2. No entanto, o desempenho dos alunos do Grupo 2 foi inferior aos do Grupo 1. Houve por parte de alguns alunos do Grupo 2 maior preocupação em responder às questões apresentadas nas tarefas com o apoio da professora do que com os seus pares e com a exploração da simulação computacional. Esse fato se expressou num baixo desempenho global do grupo. A simulação computacional foi utilizada de forma mais lúdica, mas improdutiva por alguns alunos desse grupo. Estes resultados vão ao encontro dos que foram obtidos por Cunha et al. (2014), que mostraram que quando o professor é muito intervencionista, dá muitas informações aos alunos sobre a Simulação Computacional ou se dá respostas imediatas às perguntas dos alunos, privando os alunos da oportunidade de obter por si mesmos as respostas pode levar a situações de não envolvimento ou de diminuição do envolvimento produtivo dos alunos. No Grupo 2, o número de alunos sem computador pessoal era superior ao do Grupo 1 o que pode ter influenciado a exploração da simulação numa vertente mais lúdica do que investigativa. Contudo, a maior orientação da tarefa por parte da professora parece ter tido um efeito negativo em alguns alunos. Estes se apoiaram mais na professora do que na exploração da simulação computacional. Não houve tanto empenho de alguns alunos em refletir sobre o que era necessário para resolver as tarefas, alterando as variáveis independentes na simulação e observando o efeito nas variáveis dependentes. Apoiaram-se mais na professora para resolver a tarefa e utilizaram a simulação computacional mais como diversão fazendo explodir inúmeras vezes a câmara do simulador. Mas, nem por isso, alguns alunos observaram com atenção a alteração das variáveis durante a compressão. A maior orientação proporcionada a alguns alunos parece 
ter resultado numa sensação de dependência por parte desses, em linha com o sugerido por Moli, Delserieys, Impedovo e Caster (2017). Também o fato de o grupo provir de três turmas diferentes pode ter tido alguma influência no seu comportamento e atenção na resolução das tarefas.

Relativamente à segunda questão de investigação, os alunos do Grupo 2 sentiram que lhes foi proporcionada menor autonomia na exploração da simulação do que os do Grupo 1. Estes resultados estão de acordo quer com a autonomia facultada pela professora quer com o tempo de trabalho autônomo.

\section{CONSIDERAÇões FINAIS}

O objetivo deste estudo foi investigar a influência/eficácia da mediação do professor na aprendizagem da estrutura da matéria e das mudanças de estado físico a nível microscópico, por alunos do $5^{\circ}$. ano de escolaridade.

De modo a responder às questões de investigação: "Qual a influência/eficácia da mediação do professor, em tarefas com igual orientação, na compreensão das mudanças de estado físico da matéria, a nível corpuscular, por alunos do $5^{\circ}$. ano de escolaridade" e "Que avaliação o aluno atribui à autonomia dada pela professora?" foi analisada e avaliada: 1) a mediação efetuada pela professora, em dois grupos de alunos, durante a aula de exploração da simulação computacional; 2) a aprendizagem dos alunos; 3) a percepção dos alunos sobre o clima de sala de aula e autonomia dada pela professora.

O estudo incidiu em dois grupos de alunos de igual número que exploraram a simulação computacional States-of-matter-basics da PhET, para estudar a natureza corpuscular da matéria e a alteração dos estados físicos por alteração da temperatura e da compressão.

Relativamente à primeira questão de investigação, conclui-se que uma maior orientação da exploração da simulação computacional por parte da professora parece ter resultado num pior desempenho na resolução das tarefas pelos alunos e menor aprendizagem dos alunos.

Relativamente à segunda questão de investigação, concluiu-se que os alunos que tiveram menos tempo para trabalho autônomo e menor autonomia facultada pela professora foram os que sentiram que lhes foi proporcionada menor autonomia, ou seja, a percepção de autonomia dos alunos é coerente, quer com o tempo de trabalho autônomo, quer com a autonomia proporcionada pela professora.

Algumas diferenças observadas nos dois grupos, quer em termos de experiência com computadores, quer em termos de turma de proveniência, podem ter tido alguma influência no desempenho das tarefas para além da maior orientação da tarefa e da orientação da exploração da simulação computacional por parte da professora.

São necessários mais estudos sobre a influência da mediação do professor em sala de aula com exploração de simulações computacionais pelos alunos, principalmente os desse nível etário de modo a poder comprovar ou não os nossos resultados. 


\section{REFERÊNCIAS}

ALFIERI, L., BROOKS, P. J., ALDRICH N. J., TENENBAUM H. R. Does discovery based instruction enhance learning? Journal of Educational Psychology, v. 103, n. 1, p. $1-18,2011$.

BARDIN, L. Análise de Conteúdo. Lisboa, Portugal: Edições 70, 2009.

COSTA, C., GONÇALVES, R. Observar práticas de ensino de álgebra linear. In: J. Bernardino Lopes, Clara Viegas, Alexandre Pinto (Orgs.). Melhorar práticas de ensino de Ciências e Tecnologia (p. 129-139). Lisboa: Edições Sílabo, 2018.

CRAVINO, J. P. Uso de narrações multimodais na investigação em didática de Ciências e Tecnologia. In: J. Bernardino Lopes, Clara Viegas, Alexandre Pinto (Orgs.), Melhorar práticas de ensino de Ciências e Tecnologia (p. 61-70). Lisboa: Edições Sílabo, 2018.

CUNHA, A. E., SARAIVA. E., SANTOS C. A., DINIS, F., LOPES, J. B. Teacher mediation actions and students' productive engagement during the use of computer simulations in physical science classrooms. Procedia Technology, n. 13, p. 76-85, 2014.

DE JONG, T., VAN JOOLINGEN, W. R. Scientific discovery learning with computer simulations of conceptual domains. Review of Educational Research, v. 68, n. 2, p. 179201, 1998.

ENGLE R. A., CONANT F. R. Guiding Principles for Fostering Productive Disciplinary Engagement: Explaining an Emergent Argument in a Community of Learners Classroom. Cognition and Instruction, v. 20, n. 4, p. 399-483, 2002.

HSU, Y., GAO, Y., LIU, T. C., SWELLER, J. Interactions between Levels of Instructional Detail and Expertise When Learning with Computer Simulations. Educational Technology \& Society, v. 18, n. 4, p. 113-127, 2015.

LÖFGREN L., HELLDÉN G. Following young student's understanding of three phenomena in which transformations of matter occur. International Journal of Science and Mathematics Education, v. 6, p. 481-504, 2008.

LOPES, B., CRAVINO, J. P., SILVA, A. A. (2010a). Effective Teaching for intended Learning Outcomes in Science and Tecnology. USA: Nova Science Publishers, 2010a.

LOPES, J. B., CRAVINO, J. P., SILVA, A. A. Effective teaching for intended learning outcomes in science and technology (Metilost). New York: Nova Science Publishers, 2010. 
LOPES, J. B. Uso de narrações multimodais no desenvolvimento profissional. In: J. Bernardino Lopes, Clara Viegas, Alexandre Pinto (Orgs.), Melhorar práticas de ensino de Ciências e Tecnologia (p. 35-44). Lisboa: Edições Sílabo, 2018.

LOPES, J. B., SILVA, A. A., CRAVINO, J. P., SANTOS, C. A., CUNHA, A., PINTO, A., SILVA, A., VIEGAS, C. SARAIVA, E., BRANCO, M. J. Constructing and Using Multimodal Narratives to Research in Science Education: Contributions Based on Practical Classroom. Research in Science Education, v. 44, n. 3, p. 415-438, 2014.

LOPES, J. B., VIEGAS, C., PINTO, A. (Orgs.). Narrações Multimodais: o que são e para que servem. In: Melhorar práticas de ensino de Ciências e Tecnologia (p. 21-31). Lisboa: Edições Sílabo, 2018.

MOLI, L., DELSERIEYS, A. P., IMPEDOVO, M. A., CASTERA, J. "Learning density in Vanuatu high school with computer simulation: Influence of different levels of guidance. Education and Information Technologies, v. 22, n. 4, p. 1947-1964, 2017.

MORAIS, C., PAIVA, J. Simulação digital e actividades experimentais em Físico-Químicas. Estudo piloto sobre o impacto do recurso "Ponto de Fusão e ponto de ebulição" no $7^{\circ}$. ano de escolaridade. Sísifo. Revista de Ciências da Educação, n. 3, p. 101-112, 2017.

NAKHLEDH, M.; SAMARAPUNGAVAN, A. Elementary school children's beliefs about matter. Journal of Research in Science Teaching, v. 36, n. 7, p. 777-805, 1999.

NOVAC, J. D. Results and Implications of a 12-Year Longitudinal Study of Science Concept Learning. Research in Science Education, v. 35, p. 23-40, 2005.

NOVAC, J. D., MUSONDA, D. A. A twelve-year longitudinal study of science concept learning. American Educacional Research Journal, v. 8 n. 1, 117-153, 1991.

OLYMPIOU, G., ZACHARIAS, Z., DE JONG, T. Making the invisible visible: Enhancing students' conceptual understanding by introducing representations of abstract objects in a simulation. Instructional Science, n. 41, p. 575-596, 2013.

OSBORNE, J., DILLON, J. Good practice in science teaching: What research has to say? New York, NY: Open University Press, 2010.

ÖZMEN, H. A. Cross-National Review of the Studies on the Particulate Nature of Matterand Related Concepts. Eurasian Journal of Physical \& Chemistry Education, v. 5, n. 2, p. 81-110, 2013.

SMETANA, L. K., BELL, R. L. Computer simulations to support science instruction and learning: A critical review of the literature. International Journal of Science Education, v. 34 n. 9, p. 1.337-1.370, 2012. 
SOARES, A. A. Olhares. Narrações multimodais na formação e desenvolvimento profissional do professor. In: J. Bernardino Lopes, Clara Viegas, Alexandre Pinto (Orgs.). Melhorar práticas de ensino de Ciências e Tecnologia (p. 243-244). Lisboa: Edições Sílabo, 2018.

TORRES, J., VASCONCELOS, C. Natureza da ciência e modelos científicos: um estudo com futuros professores do ensino básico. Interacções, n. 39, p. 460-47, 2015.

TREAGUST, D. F., CHITTLEBOROUGH G., MAMIALA T.L. Students' understanding of the role of scientific models in learning science. International Journal of Science Education, v. 24, n. 4, p. 357-368, 2002.

WILLIAMS, G. C., \& DECI, E. L. "Internalization of biopsychosocial values by medical students: A Test of Self-Determination Theory". Journal of Personality and Social Psychology, v. 70, n. 4, p. 767-779, 1996.

\section{Dados dos Autores}

\section{Fátima Maria AraúJo}

Universidade de Trás-os-Montes e Alto Douro. Vila Real - Portugal.

E-mail:fatimamariaaraujo@gmail.com

\section{J.BERNARDino LOPES}

Doutor em Física/Didáctica da Física. Professor da Universidade de Trás-os-Montes e Alto Douro. Vila Real - Portugal. Centro de Investigação "Didática e Tecnologia na Formação de Formadores". Universidade de Aveiro.E-mail: blopes@utad.pt

\section{Armando Soares}

Doutor em Física. Professor da Universidade de Trás-os-Montes e Alto Douro. Vila Real Portugal. Investigador no LAETA/ENEGI-UTAD, Universidade de Trás-os-Montes e Alto Douro. Vila Real - Portugal.E-mail: asoares@utad.pt

\section{José Paulo Cravino}

Doutor em Física/Didáctica da Física. Professor da Universidade de Trás-os-Montes e Alto Douro. Vila Real - Portugal. Investigador do Centro de Investigação Didática e Tecnologia na Formação de Formadores. Aveiro - Portugal. E-mail: jcravino@utad.pt

Submetido em: 21-12-2018

Aceito em: 21-3-2019 